\title{
Supporting chronic pain management across provincial and territorial health systems in Canada: Findings from two stakeholder dialogues
}

\author{
Michael G Wilson $\mathrm{PhD}^{1,2,3}$, John N Lavis MD PhD ${ }^{1,2,3,4,5}$, Moriah E Ellen MBA PhD ${ }^{6,7}$
}

MG Wilson, JN Lavis, ME Ellen. Supporting chronic pain management across provincial and territorial health systems in Canada: Findings from two stakeholder dialogues. Pain Res Manag 2015;20(5):269-279.

BACKGROUND: Chronic pain is a serious health problem given its prevalence, associated disability, impact on quality of life and the costs associated with the extensive use of health care services by individuals living with it. OBJECTIVE: To summarize the research evidence and elicit health system policymakers', stakeholders' and researchers' tacit knowledge and views about improving chronic pain management in Canada and engaging provincial and territorial health system decision makers in supporting comprehensive chronic pain management in Canada.

METHODS: For these two topics, the global and local research evidence regarding each of the two problems were synthesized in evidence briefs. Three options were generated for addressing each problem, and implementation considerations were assessed. A stakeholder dialogue regarding each topic was convened (with 29 participants in total) and the deliberations were synthesized.

RESULTS: To inform the first stakeholder dialogue, the authors found that systematic reviews supported the use of evidence-based tools for strengthening chronic pain management, including patient education, self-management supports, interventions to implement guidelines and multidisciplinary approaches to pain management. While research evidence about patient registries/treatment-monitoring systems is limited, many dialogue participants argued that a registry/system is needed. Many saw a registry as a precondition for moving forward with other options, including creating a national network of chronic pain centres with a coordinating 'hub' to provide chronic pain-related decision support and a crosspayer, cross-discipline model of patient-centred primary health care-based chronic pain management. For the second dialogue, systematic reviews indicated that traditional media can be used to positively influence individual health-related behaviours, and that multistakeholder partnerships can contribute to increasing attention devoted to issues on policy agendas. Dialogue participants emphasized the need to mobilize behind an effort to build a national network that would bring together existing organizations and committed individuals.

CONCLUSIONS: Developing a national network and, thereafter, a national pain strategy are important initiatives that garnered broad-based support during the dialogues. Efforts toward achieving this goal have been made since convening the dialogues.

Key Words: Canada; Chronic pain; Dialogue; Health systems; Pain management

Chronic pain is a serious health problem given its prevalence, associated disability, impact on quality of life, and the costs associated with extensive use of health care services (1-5). Approximately one in five Canadian adults experience chronic pain $(5,6)$, but it often goes

\author{
Soutenir la gestion de la douleur chronique dans \\ les systèmes de santé provinciaux et territoriaux : \\ les résultats de deux dialogues entre intervenants
}

HISTORIQUE : La douleur chronique est un grave problème de santé en raison de sa prévalence, des incapacités qui s'y associent, de ses répercussions sur la qualité de vie et des coûts engendrés par l'énorme utilisation des services de santé qui s'y associent.

OBJECTIF : Résumer les données de recherche et obtenir les connaissances tacites et les points de vue des décideurs, des intervenants et des chercheurs sur l'amélioration de la gestion de la douleur chronique au Canada et inciter les décideurs provinciaux et territoriaux du système de la santé à soutenir la gestion complète de la douleur chronique au Canada. MÉTHODOLOGIE : Les chercheurs ont synthétisé les données de recherche mondiales et locales sur ces deux problèmes. Ils ont proposé trois possibilités pour régler chaque problème et ont évalué les considérations en matière de mise en œuvre. Ils ont organisé un dialogue entre intervenants sur chacun des sujets (auquel 29 participants ont assisté au total) et synthétisé les délibérations.

RÉSULTATS : Pour corroborer le premier dialogue entre intervenants, les auteurs ont découvert que des analyses systématiques soutenaient les outils fondés sur des données factuelles pour renforcer la gestion de la douleur chronique, y compris l'éducation des patients, l'appui à l'autogestion, les interventions pour adopter des directives et des approches multidisciplinaires de la gestion de la douleur. Les données de la recherche sur les registres et les systèmes de surveillance des traitements des patients sont limitées, mais de nombreux participants au dialogue avançaient que ce registre ou ce système s'impose. Bon nombre considéraient le registre nécessaire pour poursuivre d'autres projets, y compris la création d'un réseau national de centres de la douleur chronique doté d'un carrefour pour offrir un soutien aux décisions liées à la douleur chronique et un modèle interdisciplinaire et interpayeur de gestion de la douleur chronique fondé sur un système de soins de première ligne axé sur le patient. Dans le cadre du deuxième dialogue, les analyses systématiques indiquaient que les médias traditionnels peuvent contribuer à favoriser les comportements positifs en matière de santé et que les partenariats avec de multiples intervenants peuvent contribuer à accroître l'intérêt envers les enjeux figurant aux programmes politiques. Les participants au dialogue ont souligné la nécessité de se mobiliser pour créer un réseau national rassemblant les organisations en place et des personnes engagées.

CONCLUSIONS : La mise sur pied d'un réseau national suivi d'une stratégie nationale de la douleur a suscité un soutien généralisé pendant les dialogues. Des mesures en vue de réaliser ces objectifs ont été prises depuis.

unrecognized and/or is undertreated $(7,8)$. Prevalence increases with age, with some estimates indicating that as many as $65 \%$ of community-dwelling older adults and $80 \%$ of those living in long-term care facilities experience chronic pain $(5,6)$. Furthermore, quality of life for

${ }^{1}$ McMaster Health Forum; ${ }^{2}$ Department of Clinical Epidemiology and Biostatistics; ${ }^{3}$ Centre for Health Economics and Policy Analysis;

${ }^{4}$ Department of Political Science, McMaster University, Hamilton, Ontario; ${ }^{5}$ Department of Global Health and Population, Harvard School of

Public Health, Boston, Massachusetts, USA; ${ }^{6}$ Jerusalem College of Technology, Jerusalem; ${ }^{7}$ Israeli Center for Technology Assessment in

Health Care, Tel Hashomer, Israel

Correspondence: Dr Michael G Wilson, McMaster University, 1280 Main Street West, CRL-223, Hamilton, Ontario L8S 4 K1.

Telephone 905-525-9140 ext 22171, fax 905-521-2721, e-mail wilsom2@mcmaster.ca 
individuals with chronic pain has been found to be lower than for those with most other chronic diseases (1). The financial impact of chronic pain in terms of health care expenditures and productivity costs has been estimated to be $\$ 56$ to $\$ 60$ billion per year in Canada (9).

To support and provide better care for Canadians affected by chronic pain, there is a need to identify how provinces and territories across the country may individually, as well as collectively, strengthen chronic pain management. One approach to addressing health system issues such as chronic pain is to convene stakeholder dialogues, in which the overriding objective is to support evidence-informed policymaking by pairing the best available research evidence with a robust deliberative process that gives voice to the tacit knowledge and real world views and experiences of those involved in and/or affected by the issue. In general, stakeholder dialogues convene health system stakeholders (eg, government officials, professional and community leaders, patients/citizens/groups representing them and researchers) for deliberations with the goal of supporting participants to champion creative efforts to address a pressing health system problem within their respective constituencies (10). Specifically, dialogues provide stakeholders with the opportunity to bring their tacit knowledge and their own views and experiences to bear on a pressing health system problem, options that would address it and consideration of implementation issues. Each dialogue was informed by an evidence or issue brief that mobilized the best available research evidence about each of these components (an issue brief uses the same approach as an evidence brief, but draws on findings from a previously conducted synthesis of the evidence) (10).

To foster these efforts, the Community Alliances for Health Research and Knowledge Translation on Pain partnered with and provided funding to the McMaster Health Forum (www.mcmasterhealthforum.org) in 2009. It was to act as a neutral convenor for a stakeholder dialogue focused on strengthening chronic pain management in Canada. This dialogue was followed by another in April 2011 (again with funding from CAHR-pain to the McMaster Health Forum) to build on a key finding from the first dialogue - the need to more systematically engage health system decision-makers in supporting comprehensive chronic pain management in provincial and territorial health systems in Canada. Specifically, the challenges of engaging policymakers in the first dialogue led to broad-based consensus among participants that long-term sustainable action is constrained by a lack of attention devoted to chronic pain by health system decision-makers. In the present article, we present the key findings from the two stakeholder dialogues and the briefs that were prepared to inform them $(11,12)$. We also provide an overview of examples of progress that have been made since the dialogues were convened to draw attention to the types of actions that have been or are being taken to address this pressing health system issue.

\section{METHODS}

The two stakeholder dialogues were convened on December 9, 2009 and April 11, 2011, in Hamilton, Ontario. Briefs sent to participants in advance were prepared by the McMaster Health Forum working in collaboration with an interdisciplinary steering committee. The methods used for preparing the briefs and convening the dialogues are described below. A detailed article describing evidence briefs and stakeholder dialogues is also available for those interested in more detail about the approach (10).

\section{Preparing the evidence and issue briefs}

Each of the briefs was prepared through four steps. First, a steering committee comprising representatives from partner organizations and stakeholder groups was convened. The role of the steering committee was to engage with the McMaster Health Forum to provide guidance and expert advice across all stages of the process. In collaboration with the steering committee, terms of reference were developed for each of the briefs. These provided a preliminary outline framing the problem, three options for addressing it and implementation considerations. In the second step, key informant interviews were conducted (nine for the evidence brief and 11 for the issue brief) with policymakers, managers (eg, from health regions, health care institutions and community-based organizations), stakeholders (eg, from interest groups, provider associations or other stakeholder groups) and researchers, who were actively engaged in the issue of chronic pain. The terms of reference were iteratively revised based on feedback from the key informants and the steering committee and then used to guide the writing of each brief. The key informants were also asked to identify literature that would be relevant to preparing the briefs.

Third, for each brief, relevant research evidence regarding the problem, options and implementation considerations was identified, selected, appraised and synthesized. Whenever possible, research evidence was drawn from systematic reviews and, occasionally, from single studies when reviews were not identified. Published literature was identified by searching PubMed using the health services research search filters for appropriateness, process assessments, outcomes assessments and qualitative research. In addition, grey literature was searched for by reviewing the websites of a number of Canadian and international organizations (13-21). To identify research evidence about the three options in each of the briefs, Health Systems Evidence (www.healthsystemsevidence.org) was searched. Health Systems Evidence is a continuously updated database, which in January 2015 contained $>4200$ systematic reviews and $>2200$ economic evaluations of health service delivery, including consideration of financial and governance arrangements within health systems. Health Systems Evidence identifies documents from several sources including the Cochrane Database of Systematic Reviews (for systematic reviews of effects) and the Centre for Reviews and Dissemination (for systematic reviews of effects and economic evaluations) (22). The reviews and economic evaluations were identified by searching Health Systems Evidence for chronic pain in the title and abstract and by searching topic categories addressing features of each of the options.

The searches were reviewed for relevance by the lead author of each brief (JNL for the first brief and MGW for the second brief). For each systematic review, the focus of the review, key findings, the last year the literature was searched, the methodological quality (based on AMSTAR [23] ratings that are provided for all reviews contained in Health Systems Evidence), the proportion of included studies that were conducted in Canada and the proportion of included studies focused on chronic pain were extracted. For any reviews that had not been previously quality appraised using AMSTAR, two reviewers independently completed an assessment.

Fourth, key findings in the form of an evidence brief (for the first dialogue) and an issue brief (for the second dialogue) were synthesized. Specifically, the briefs were drafted in such a way as to present concisely and in accessible language the global and local research evidence. The final version of the briefs consisted of a one-page summary of key messages followed by a more detailed description of: the problem; three options (including the benefits, harms and costs of the options as well as key elements of and stakeholder experiences with them); and possible barriers to implementation of the options at the levels of individuals, providers, organizations and systems. A merit review process was then undertaken for each brief with a small number of policymakers, stakeholders and researchers to ensure each brief's system relevance and scientific rigour.

\section{Convening the stakeholder dialogues}

Working collaboratively with the steering committees, health system stakeholders were identified (government officials, professional and community leaders, groups representing people living with chronic pain and other stakeholders, as well as researchers). Participants were invited who had the ability to: bring unique views and experiences to bear on the challenge and learn from the research evidence and from others' views and experiences; and champion within their respective constituencies actions that would address the challenge creatively. Participants were identified by reviewing government directories and the websites of relevant organizations and from suggestions provided 
TABLE 1

Features of the problem of chronic pain management (and its causes)*

Issue Factors contributing to the issue

Significant burden of chronic • Approximately one in five Canadian adults suffer from chronic pain $(5,6)$

pain that the health care - The mean age of those with chronic pain (47.7 years) was found to be significantly higher than the mean age of those without system must prevent chronic pain (42.4 years) (5)

or manage $\quad$ - Canadian Community Health Survey data from 2005 indicates that $27 \%$ of Canadians aged $\geq 65$ years and living in private households reported chronic pain, compared with $16 \%$ of people aged 18 to 64 years (30)

- Prevalence increases with age (as many as $65 \%$ of community-dwelling older adults and $80 \%$ of those living in long-term care facilities have chronic pain) $(5,6)$

- In 2008, $9.7 \%$ of Canadians 35 to 44 years of age reported that they usually have pain or discomfort that is moderate or severe, which was higher than the $8.6 \%$ reported in 2003 (31)

- Quality of life for people with chronic pain has been found to be lower than most other chronic diseases (1)

Inconsistent access to effective approaches to chronic pain management

- Little is known about the degree to which Canadians are receiving effective components of comprehensive chronic pain management (particularly outside multidisciplinary pain clinics) or about health care providers' beliefs about and use of different approaches to chronic pain management

- Effective components of comprehensive chronic pain management are available or accessible to varying degrees across Canada

$\circ 75 \%$ of multidisciplinary clinics offered at least one type of interventional technique (eg, peripheral nerve block) and $78 \%$ at least one type of physical therapy (eg, individualized exercise program)

only $40 \%$ of multidisciplinary pain clinics in 2004-2005 offered programs that included support for self-management (eg, coping strategies, neck care, yoga, medication and stress management) despite evidence of their effectiveness and cost-effectiveness

a Canadian study conducted in 2005-2006 found that $24 \%$ of multidisciplinary pain clinics did not offer any psychological treatments (32)

Health system arrangements that limit optimal chronic pain management

- A variety of health system arrangements do not support chronic pain management:

- limited support for self-management despite having been shown to be effective and cost-effective $(33,34)$;

- inadequate access to primary health care providers for some Canadians and inadequate management of chronic pain by some primary health care providers and specialists, which may be related to inadequate training and continuing professional development;

- many non-physician health care providers (including community-based rehabilitation practitioners) are not actively engaged in chronic pain management at the primary health care level;

o inequitable geographical access to regional multidisciplinary chronic pain management centres;

- lack of a monitoring system to identify patterns of under- and over-utilization of programs, services and drugs;

- financial arrangements that encourage some forms of care (eg, injections) but not others (eg, counselling and monitoring) and that create financial barriers to access for some people living with chronic pain; and

- governance arrangements that do not ensure the credentialing of chronic pain providers and clinics

- Numerous clinical practice guidelines exist for the management of chronic pain, yet there is no 'home' for the development/updating, implementation and monitoring of these guidelines

Lack of coordinated approaches to support implementation of chronic pain management guidelines

${ }^{*}$ The information in this table is based on what was available at the time of publication of the evidence brief (December 2009)

by members of the steering committee (given their expertise and experience working in the area of chronic pain).

Both dialogues were facilitated by one of the authors (JNL) and included deliberations about the topics addressed in each of three sections of the brief (problem, options and implementation considerations) as well as a fourth deliberation about steps that may be taken by participants' constituencies. Briefs were sent to participants two weeks before the dialogue and it was requested that they read it before arriving so that all participants would face a 'level playing field' in terms of background information and time would not need to be devoted to reviewing the detailed contents of the brief. The goal was not to aim for consensus but rather to provide a space where diverging opinions could be shared and discussed and to identify where synergistic efforts among stakeholders to address the problem might be possible. In addition, each dialogue followed the Chatham House rule (ie, information used during the meeting may be used, but neither the identity nor the affiliation of participants were to be revealed). Finally, the dialogues were not recorded but notes were taken by the facilitator and students assisting with each dialogue. These notes were used to draft summaries of each dialogue that highlighted the key themes that emerged during each deliberation, points of disagreement or general consensus, and the types of action that participants thought could be taken following the dialogue (the identities of participants were kept confidential in the dialogue summaries).

\section{RESULTS}

Topic 1: Supporting chronic pain management across provincial and territorial health systems in Canada

The first stakeholder dialogue addressed the issue of chronic pain management across Canada. We present below a summary of the key findings from the evidence brief and the key themes of the deliberations. For those interested in additional information, the evidence brief (12) and dialogue summary (24) are available on the McMaster Health Forum website (www.mcmasterhealthforum.org).

Key findings from the evidence brief: The challenge of strengthening chronic pain management in provincial and territorial health systems can be understood by considering four sets of inter-related issues, outlined along with a summary of contributing factors in Table 1. Many options were available to address the issues. To promote discussion about the pros and cons of potentially viable options, we selected three, which we outline in Table 2, along with a summary of key findings. Finally, we identified implementation barriers at the level of individuals, care providers and systems, as well as possible strategies to address the barriers, which we outline in Table 3. Summary of dialogue 1: The dialogue brought together a diverse group of 13 stakeholders (two policymakers/managers, three health care provider association/group representatives, four researchers and four other stakeholders) from across Canada. The group was smaller than our target size of 18 to 22 , largely due to the difficulty 
TABLE 2

Three options for better supporting chronic pain management*

\begin{tabular}{|c|c|}
\hline Option & cus and elements \\
\hline $\begin{array}{l}\text { 1. Create a model } \\
\text { patient registry/ } \\
\text { treatment- } \\
\text { monitoring system } \\
\text { in a single } \\
\text { jurisdiction }\end{array}$ & $\begin{array}{l}\text { - This option focuses on: } \\
\text { identifying what services are being offered to whom (ie, what types of patients), by whom } \\
\text { (eg, what disciplines), and how frequently (with appropriate attention to privacy concerns); } \\
\text { - identifying both under- and over-utilization; } \\
\text { monitoring efforts to improve service delivery and evaluating their impacts; and } \\
\text { - publicly reporting opportunities for improvement } \\
\text { To further understand this option, it is useful to consider it according to four key health system elements } \\
\circ \text { patient registries; } \\
\text { treatment-monitoring systems; } \\
\circ \text { privacy issues pertaining to patient registries/treatment-monitoring systems; and } \\
\circ \text { public reporting of aggregated data }\end{array}$ \\
\hline $\begin{array}{l}\text { Create a national } \\
\text { network of centres } \\
\text { with a coordinating } \\
\text { 'hub' to provide } \\
\text { chronic pain-related } \\
\text { decision-support }\end{array}$ & $\begin{array}{l}\text { - The function/focus of a coordinating hub would be to: } \\
\text { analyze data about treatment patterns (which can include the analysis of data from a patient } \\
\text { registry/treatment-monitoring system, which was the focus of the preceding option); } \\
\text { synthesize research evidence; } \\
\text { develop and disseminate resources and tools to support self-management; } \\
\text { develop and disseminate clinical practice guidelines and other resources and tools to support } \\
\text { providers and organizations in prevention, early identification, and ongoing treatment; } \\
\text { offer support to undergraduate professional training programs; } \\
\text { offer continuing professional development and other strategies to support evidence-based care } \\
\text { (both for single disciplines and multidisciplinary teams); and } \\
\text { monitor efforts to improve care (across the full range of payers and the full continuum of care, } \\
\text { including primary health care, postsurgical care, etc) and evaluate their impacts } \\
\text { - This option can be further understood by considering the effectiveness of the tools and resources } \\
\text { the hub would provide, including: } \\
\text { tools to support self-management (eg, education for people living with chronic pain, decision aids, } \\
\text { personal health records, peer support and telephone support); } \\
\text { interventions to support the dissemination of clinical practice guidelines; } \\
\text { support for undergraduate professional training programs; } \\
\text { continuing professional development and other strategies to support evidence-based care; and } \\
\text { monitoring efforts to improve care and evaluate their impacts }\end{array}$ \\
\hline
\end{tabular}

Summary of key findings

- Substantial uncertainty exists

regarding this option's benefits and potential harms

- No clear message was derived from an older (2006) medium-quality review about the effects of public reporting on effectiveness, safety and patient-centredness (35)

- No relevant reviews were identified about privacy issues pertaining to a patient registry/treatment-monitoring system

- Synthesized research evidence is available to support the use of a range of evidence-based tools and resources:

- Two high-quality reviews and one medium-quality review focused on patient education and showed favourable results in terms of pain reduction (however, all reviews are more than five years old).

- Other reviews identified some benefits and no harms with respect to other self-management supports (eg, patient education, decision aids, personal health records, peer support and telephone support) (36-46), interventions to support the implementation of clinical practice guidelines (multifaceted interventions were found to generally be most effective) (12), and continuing professional development to support evidencebased care (12)

- No reviews were identified that relate directly to the concept of a hub.

- Several reviews relate to cross-

3. Broker and - This option focuses on rewarding:

$\circ$ quality, such as by re-balancing fee schedules away from procedures and toward payment for the time demands associated with assessment, management, support, and dealing with payers and employers, and by accrediting chronic pain 'specialist' providers or centres; and

implementation of a cross-payer, cross-discipline model of patientcentred primary health care-based chronic pain management

o efficiency, such as by engaging the most cost-effective providers and by providing tiered support from telecommunications to in-person interactions, and through tiered referrals from primary health care to accredited regional multidisciplinary pain clinics

- This system redesign has a number of health system elements that each need to be considered:

o cross-payer models of patient-centred primary health care-based chronic pain management;

- cross-discipline models of patient-centred primary health care-based chronic pain management that address the full spectrum of comprehensive care (eg, prevention, early intervention, treatment, management and rehabilitation);

o rewards for quality and efficiency in primary health care;

$\circ$ fee schedules that consider the time demands associated with primary and secondary prevention, treatment, management and rehabilitation, as well as dealing with payers and employers;

- accrediting chronic pain 'specialist' providers or centres;

o engaging the most cost-effective providers; and

o providing tiered support from telecommunications to in-person interactions and through tiered referrals from primary health care to accredited regional multidisciplinary chronic pain management centres discipline models of care.

- Three medium-quality reviews and one high-quality review that relate to multidisciplinary approaches to pain management found medium to strong evidence for improvements in patient function (47)

- Another recent (2009) high-quality review showed no difference in patient outcomes between those receiving multidisciplinary rehabilitation and those in control groups (43)

- No recent or high-quality reviews were identified about cross-payer models of patient-centred primary health care

\footnotetext{
*The findings in this table are based on what was available at the time of publication of the evidence brief (December 2009)
} 
TABLE 3

Potential barriers to implementing the options in the evidence brief*

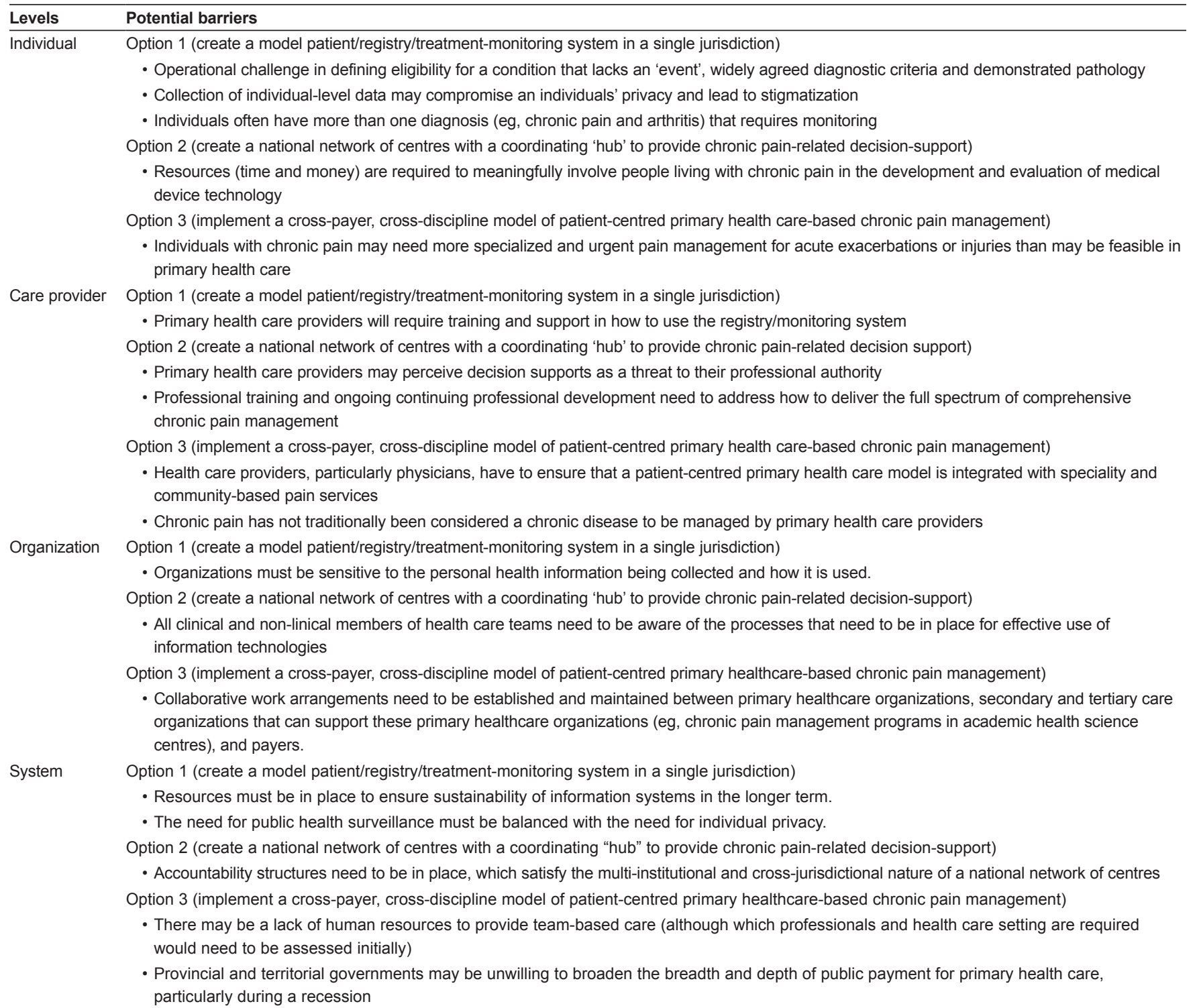

Possible strategies to address the barriers

- Initiate a national stakeholder-engagement process to raise awareness of health system issues within the chronic pain community and to raise awareness of chronic pain issues within the health policy and systems community

- This approach could be informed by the work done in Australia, which was the first country in the world to develop a national strategy and framework for the treatment and management of pain (27), which was the key outcome of a National Pain Summit in 2010 (48)

- A similar approach in Canada might mobilize evidence from sources including (but not limited to) academic pain centres, interest groups representing people living with chronic pain and the public, health provider associations and other sources.

*The information in this table is based on what was available at the time of publication of the evidence brief (December 2009)

with engaging policymakers/managers from across the country. This highlighted the need for a follow-up dialogue about how to engage health system decision makers in supporting comprehensive chronic pain management.

In deliberating about the problem, several dialogue participants argued that significant stigma was associated with chronic pain and that this stigma translated into a lack of legitimacy of the need for care, which in turn added to the burden of chronic pain. Some of these dialogue participants argued that "no recognition of chronic pain as a disease" was a significant dimension of the problem; however, other dialogue participants were not convinced by this argument. Dialogue participants generally agreed that effective chronic pain management programs, services and drugs were not always available or accessible to all Canadians, and they also agreed that there are significant gaps in our knowledge about these shortcomings and their causes. Participants also agreed that current provincial and territorial health system arrangements do not support chronic pain management for all Canadians. As one dialogue participant said, "access is terrible and getting worse."

During the deliberation about options to address the problem, several dialogue participants argued strongly that a patient registry/ treatment-monitoring system (option 1) was definitely needed to support efforts to monitor the implementation of new approaches to organizing chronic pain management and to evaluate their impacts. Several dialogue participants saw the registry/system as a precondition for other 
TABLE 4

Features of the problem of the lack of health system decision maker engagement in supporting comprehensive chronic pain management (and its causes)*

\begin{tabular}{|c|c|}
\hline Issue & ntributing to the issue \\
\hline of & $\begin{array}{l}\text { - Chronic pain may not garner sufficient attention because it is often associated with or the result of one or more physical or psychological } \\
\text { comorbidities and, as a result, it is often seen as a symptom rather than a disease or condition in its own right (1) } \\
\text { - There is a general lack of awareness of the high prevalence of chronic pain and of comorbidities among chronic pain sufferers in Canada }\end{array}$ \\
\hline $\begin{array}{l}\text { Lack of awareness of } \\
\text { limitations in existing } \\
\text { programs and } \\
\text { services }\end{array}$ & $\begin{array}{l}\text { - General limitations in the availability of and access to primary health care services are likely } \mathrm{f} \\
\text { chronic pain, given they may be seen as more complex (and hence be less likely to be taken } \\
\text { needs for care (and hence be more likely to suffer the consequences of a lack of care), and th } \\
\text { suboptimal settings such as emergency rooms (and hence be more likely to suffer the consec } \\
\text { - While there are multidisciplinary pain clinics available in Canada, the availability is generally limit } \\
\text { typically available in urban centres (limiting access to people living in rural or remote regions) anc } \\
\text { found to be } \$ 1,462 \text { per month), which is privately financed } 95 \% \text { of the time (thereby limiting acce }\end{array}$ \\
\hline $\begin{array}{l}\text { Ith system } \\
\text { ents that } \\
\text { tention } \\
\text { ironic pain }\end{array}$ & $\begin{array}{l}\text { ty of health system arrangements contribute to the problem, including: } \\
\text { in existing delivery arrangements (eg, lack of well-established packages of care/guidelines for the management of chronic pain, lack } \\
\text { comprehensive continuum of care, and lack of integration with other models of proactive and coordinated care for chronic conditions); } \\
\text { cial arrangements (eg, lack of visibility of the public and private costs of chronic pain management and lack of financial incentives for } \\
\text { tive chronic pain management at the primary health care level); and } \\
\text { ernance arrangements (eg, lack of clear policy authority and lack of training and accreditation for health care providers and clinics to } \\
\text { er to people living with chronic pain) }\end{array}$ \\
\hline $\begin{array}{l}\text { Limited reach of exist- } \\
\text { ing efforts to engage } \\
\text { health system deci- } \\
\text { sion makers in sup- } \\
\text { porting chronic pain }\end{array}$ & $\begin{array}{l}\text { - Several efforts have been made with the goal of developing and implementing a national pain strategy including briefs from the Canadian } \\
\text { Pain Coalition and Canadian Pain Society that contained recommendations to government about the creation of a strategy (49), and } \\
\text { broad-based endorsement for a national pain strategy at the Canadian Pain Summit, which garnered significant attention (26) } \\
\text { - While initiatives exist in several provinces (eg, British Columbia, Alberta, Ontario, Quebec and the Atlantic provinces), calls for a national } \\
\text { pain strategy persist (26) }\end{array}$ \\
\hline
\end{tabular}

*The information in this table is based on what was available at the time of publication of the issue brief (April 2011)

options. Several participants also voiced strong support for the research and support functions that a national network of centres with a coordinating 'hub' (option 2) could achieve for people living with chronic pain and their providers. Many also supported the idea of a cross-discipline model of patient-centred, primary health carebased chronic pain management. This model could include: primary health care practices/clinics assuming the primary responsibility for chronic pain management; facilitated access to mentoring for these practices/clinics to support and enable them to fulfil this role; and opportunities for these practices/clinics to periodically engage multidisciplinary and multimodal secondary- and tertiary-level supports for those people living with chronic pain requiring more complex care and support.

As part of the deliberation about implementation considerations, several dialogue participants noted that prospects for success for the registry/system (option 1) would be much greater if implemented in the form of a program of research rather than as a government or regional health authority initiative. Some argued that successful implementation of a national network of centres (option 2) hinged on getting the right champions (clinicians, leaders in teaching institutions and people living with chronic pain) around the table from the beginning. Several dialogue participants suggested that brokering and supporting the implementation of a cross-discipline model (option 3) could be facilitated in the short term through demonstration projects, coupled with rigorous monitoring and evaluation, and in the long term through a systematic effort to "move beyond the early adopters."

In the last deliberation about next steps that different constituencies could take, one dialogue participant argued that governments seem unprepared to take action in the short term, so "stakeholders have to be the ones who make it happen." Several dialogue participants argued that the critical next step should be to engage those who could take action, including key opinion leaders (both those leading the push for strengthened chronic pain management and those in primary health care practices), regional health authorities and government. A number of dialogue participants argued that success stories need to be identified, their cost-effectiveness relative to the status quo studied, and the findings from this effort popularized in a systematic way.
Topic 2: Engaging health system decision makers in supporting comprehensive chronic pain management in provincial and territorial health care systems in Canada

The second dialogue was designed to build on the key finding from the first dialogue that long-term sustainable action is constrained by the lack of attention paid to chronic pain by health system decision makers. Given this, the second dialogue was focused on how to more systematically engage health system decision makers in supporting comprehensive chronic pain management in provincial and territorial health systems in Canada. For the purposes of this brief and dialogue, decision makers included policymakers (and those who support policymakers), and regional health authority staff. We present below a summary of the key findings from the issue brief and the key themes of the deliberations. For those interested in additional information, the issue brief (11) and dialogue summary (25) are available on the McMaster Health Forum website (www.mcmasterhealthforum.org).

Key findings from the issue brief: The lack of health system decision maker engagement in supporting comprehensive chronic pain management in provincial and territorial health care systems in Canada can be understood by considering four sets of inter-related issues, outlined along with a summary of contributing factors in Table 4. Similar to the first brief, to promote discussion about the pros and cons of potentially viable options, we selected three, which we outline in Table 5 along with a summary of the key findings. Finally, we identified implementation barriers at the level of individuals, care providers and systems, as well as possible strategies to address the barriers, which we outline in Table 6.

Summary of dialogue 2: The dialogue brought together 16 participants from across Canada, which included six health system decision makers, four individuals from groups representing people living with chronic pain and professionals, five researchers and one representative from another stakeholder group.

During the deliberation about the problem, most participants noted that the lack of health system decision maker engagement is largely the result of a lack of awareness of the problem. Themes related to this lack of awareness that emerged during the dialogue include: a lack of understanding of chronic pain (which in turn relates to a lack of consensus about what chronic pain actually is, and a lack 
TABLE 5

Three options for engaging health system decision makers in supporting comprehensive chronic pain management*

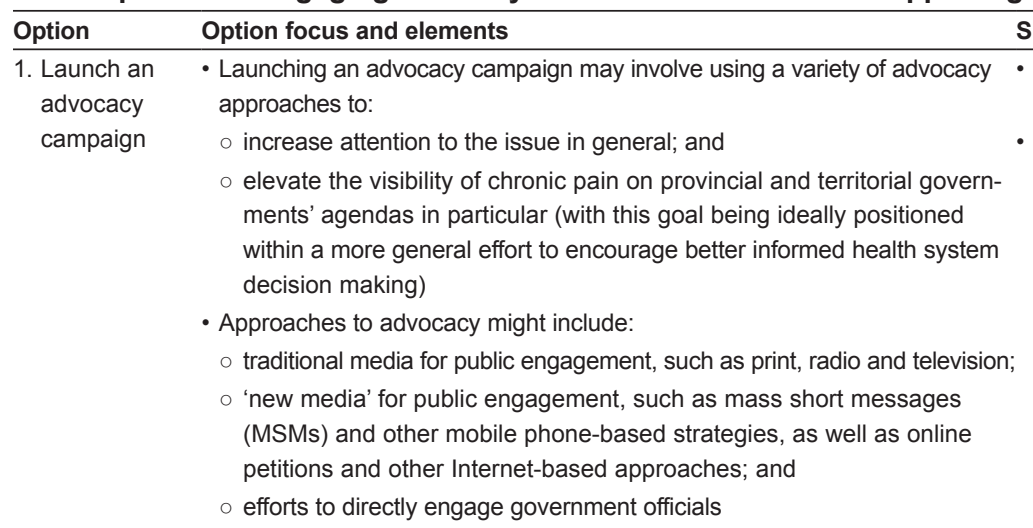

2. Create a - This option involves raising awareness and support among policymakers multistake- who could or should be paying attention to chronic pain, ideally in the holder provin- context of a broader effort to engage all relevant stakeholders in supporting cial or national improvements to chronic pain management (with the stakeholders including working group the full range of health system decision makers, health care providers, researchers and provincial/national coalitions or nongovernmental organizations)

- Elements of a multistakeholder provincial or national working group could include:

o establishing a national network of stakeholder groups with a coordinating 'hub';

o engaging key opinion leaders who can take action, both those leading the push for strengthened chronic pain management and those in primary health care practices, regional health authorities and government;

- equipping these key opinion leaders (and the stakeholder groups from which they are drawn) with the necessary tools to take action, which may in turn include:

- compelling data and stories about the current burden of chronic pain and the implications (eg, costs) of not addressing it;

- regularly updated, evidence-based packages of care/guidelines for the management of chronic pain at the primary health care level and in related fields of practice;

- mechanisms to coordinate across fields of practice and across relevant disease groups that are often linked to chronic pain; and

- periodically identified priorities for new primary and secondary research and the communication of these priorities to relevant funders

3. Develop chronic pain policy portfolios and strategic foci
- Developing policy portfolios or strategic foci would provide the opportunity to coordinate responses to chronic pain within and across governments, regional health authorities, and the stakeholder community and could include:

o engaging and liaising with other relevant policy areas within the government and regional health authorities to coordinate the development and implementation of relevant policies and programs; and

$\circ$ engaging and liaising with relevant stakeholders to inform the development and implementation of programs and services in the community

- Elements of this option might include:

- mapping what existing policy portfolios are relevant to supporting chronic pain management, particularly at the primary health care level; and

o establishing an integrated portfolio to support chronic pain management or a coordinating role that would work across other relevant portfolios and departments.

Summary of key findings

- One medium-quality systematic review found a lack of evidence about the effects of multistakeholder networks (specifically public health partnerships) on health outcomes but qualitative studies included in the review suggested that some partnerships increased the profile of health inequalities on local policy agendas (52)

- Four older systematic reviews related to engaging opinion leaders (in the clinical context), three of which were high quality (53-55) and one low quality (56)

- Each review focuses on the clinical context, but still offer helpful insights about the potential effects of using local opinion leaders who can lead the push for engaging health system decision-makers in strengthening chronic pain management

- Both of the high-quality reviews found minimal evidence about local opinion leaders, but one concluded that opinion leaders with or without another intervention were generally effective for improving appropriate care (53), and the other concluded that there was insufficient evidence to determine the effectiveness of local opinion leaders in the field of physiotherapy (54)

- The remaining two reviews similarly concluded that there is insufficient evidence to determine whether local opinion leaders are effective for supporting clinical practice $(55,56)$

No systematic reviews addressing any of the elements of this option were identified

- Key messages that emerged from previous efforts in Canada to reallocate resources and decision making to support a shift in perspective may provide helpful insight:

- In the early 1990s, the province of Prince Edward Island initiated a process of 'cross-sectoral reallocation' that emphasized "broad determinants of health, client focus in service delivery, pooling of human services, integration and coordination of services, and the establishment of regional governance" (28,57-61)

- An analysis of instruments put in place to facilitate the shift toward the broad determinants of health revealed that regional governance can help ensure integration and coordination within regions but that there is a need for a central authority to ensure equity between regions (28)

- Additional elements cited as important facilitators of the process include: fostering an organizational culture that is supportive of change; and starting with low-profile changes that can demonstrate how it can work (28)

\footnotetext{
* The findings in this table are based on what was available at the time of publication of the issue brief (April 2011)
}

of data and research evidence about its impact on Canadians and on health systems in Canada); the limited education about chronic pain provided to people living with it, health care providers and health system decision makers; and a lack of well-documented cases for why chronic pain is an issue that health system decision makers need to focus on (eg, a lack of stories about how chronic pain affects the lives 
TABLE 6

Potential barriers to implementing the options in the issue brief*

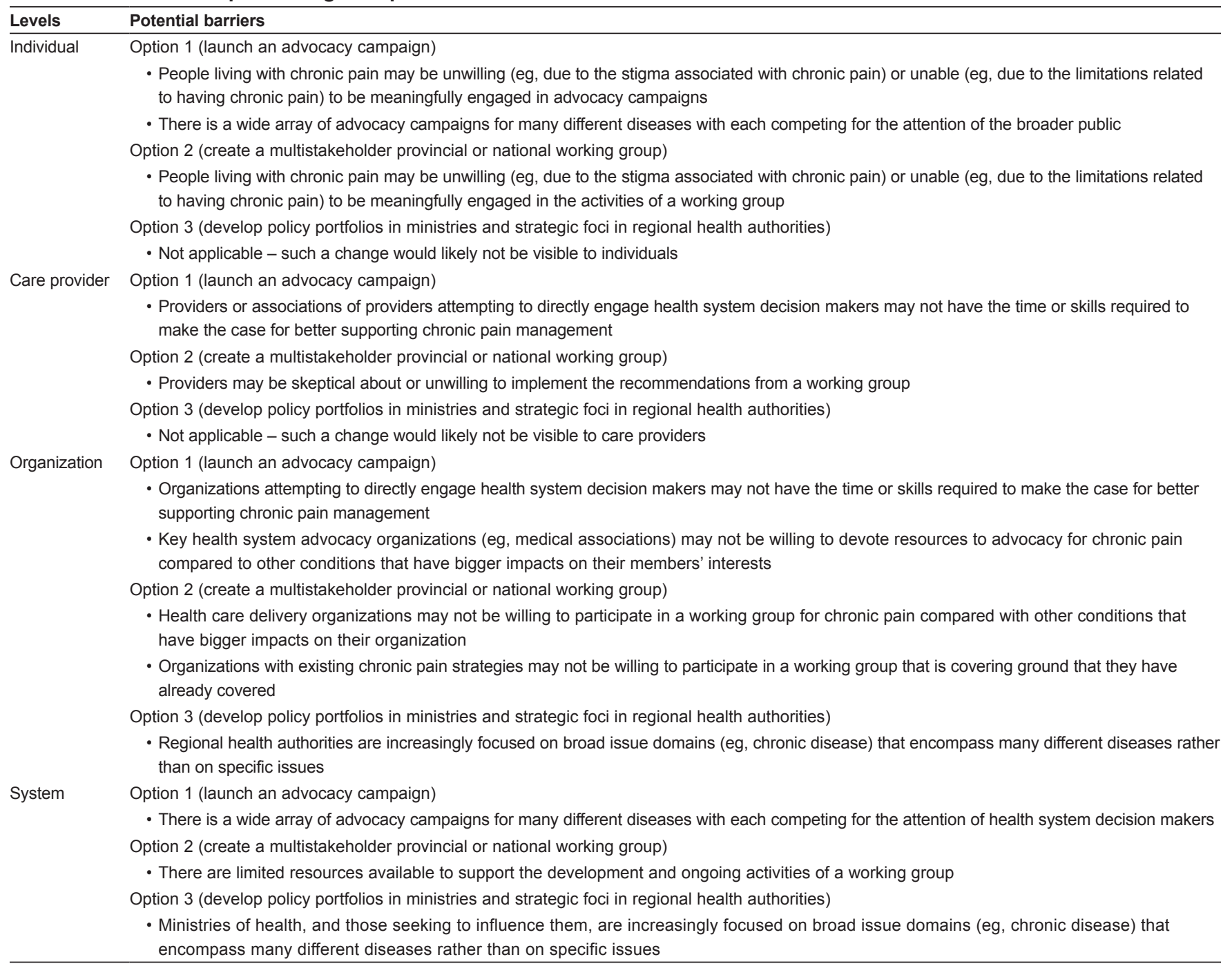

\section{Possible strategies to address the barriers}

- Given that several options may be pursued simultaneously and that option elements may be combined in different and creative ways, identifying 'cross-cutting' implementation strategies may be an important first step

- One possible cross-cutting implementation strategy may be the development, pilot testing and iterative redevelopment of a package of communication materials that highlight the ways in which chronic pain affects people's lives, the costs associated with the status quo, and success stories (and how their cost-effectiveness compares with the status quo)

*The information in this table is based on what was available at the time of publication of the issue brief (April 2011)

of those living with it, a lack of documentation of the broader economic impact of chronic pain, and a lack of documentation of success stories in chronic pain management).

In deliberating about the three options to address the problem, most dialogue participants strongly endorsed the creation of a national multi-stakeholder network. Participants indicated that such a network should be comprised of organizations and committed individuals who would work collaboratively to raise awareness about chronic pain, and increase support for and coordination in comprehensive chronic pain management. Several dialogue participants called for including in the network those involved in chronic disease management, primary health care, and other domains that have already been prioritized (particularly those that are highly relevant to people living with chronic pain). Most participants believed that an advocacy campaign would be an important function for this network. A number of dialogue participants also endorsed the idea of developing chronic pain policy portfolios within government, and strategic foci within regional health authorities. It was suggested that these would optimally be nested within broader portfolios/foci such as chronic diseases to ensure there is a clear 'anchor' for chronic pain within health systems.

Five significant challenges related to implementation were identified by dialogue participants: identifying a leadership model; ensuring the capacity and willingness of existing organizations and individuals to engage in creating and sustaining the network; weighing the advantages of working within a small group of provinces and territories to achieve some early wins, versus working across all provinces and territories simultaneously; securing the resources to design, launch and operate the network and any advocacy campaign it develops; and scaling up the efforts to identify and harness data and to produce and synthesize research evidence that supports the work of the network and the content of any advocacy campaign. 
The deliberation about next steps focused on the need to mobilize toward building a national network that would bring together existing organizations and committed individuals. Some early wins for the network may include the endorsement of a national pain strategy, which would include agreed-upon definitions. Several dialogue participants emphasized the primacy being given to an 'evidence-based' and 'grass-roots' approach, and being certain not to lose these features in a rush to a 'big bang' solution.

\section{Progress following the dialogues}

Progress has been made in several areas that were deliberated about during the stakeholder dialogues (26), including: launching an advocacy campaign (eg, a delegation went to Parliament Hill in the lead up to the Canadian Pain Summit in April 2012); the initiation of a national stakeholder-engagement process (National Pain Summit) to raise awareness of health system issues within the chronic pain community and to raise awareness of chronic pain issues within the health policy and systems community (this was highlighted as a possible implementation strategy in the first dialogue); and developing chronic pain policy portfolios and strategic foci (eg, Ontario's efforts to develop a chronic pain plan for the province). In Australia, such advocacy and stakeholder engagement efforts (eg, the National Pain Summit held there in 2010) were the main catalysts that led to them being the first country in the world to develop a national strategy and framework for the treatment and management of pain (27). Similar momentum and interest among policymakers and stakeholders seems to be building in Canada toward developing a similar strategy for the country.

\section{Principal findings}

\section{DISCUSSION}

To inform the first dialogue, we found that systematic reviews supported the use of evidence-based tools for strengthening chronic pain management, including patient education, self-management supports, interventions to implement clinical practice guidelines, and multidisciplinary approaches to pain management. While research evidence about patient registries/treatment-monitoring systems is limited, many dialogue participants argued strongly that such a system is needed. In addition, many saw a registry as a precondition for moving forward with other options, including creating a national network of chronic pain centres with a coordinating 'hub' to provide chronic pain-related decision support, and a cross-payer, cross-discipline model of patient-centred primary health care-based chronic pain management. For the second dialogue, we found systematic reviews indicating that traditional media can be used to positively influence individual health-related behaviours, and that multistakeholder partnerships can contribute to increasing the attention paid to issues regarding policy agendas. We also found evidence from previous efforts in Canada for 'cross-sectoral reallocation', which highlighted that regional governance can help ensure integration and coordination within regions (28). The evidence also indicated that fostering an organizational culture that is supportive of change, and starting with low-profile changes that can demonstrate how it can work, were important facilitators of cross-sectoral reallocation processes (28). Dialogue participants emphasized: the need to mobilize behind an effort to build a national network that would bring together existing organizations and committed individuals; an early win for the network may include the endorsement of a national pain strategy; and the need to not lose the primacy given to an 'evidence-based' and 'grass-roots' approach in a rush to a 'big bang' solution.

\section{Strengths and limitations}

Our process had two notable strengths and two important limitations. First, because we were not actively engaged in work related to chronic pain, we were able to act as neutral convenors of the stakeholder dialogues, which allowed us to better achieve our overriding objective of supporting evidence-informed policymaking. The second strength is that we paired the best available research evidence with a robust deliberative process that gives voice to the tacit knowledge and real world views and experiences of those involved in and/or affected by the issue. The main limitation of the present paper is that the findings reported from the evidence and issue briefs are based on the research evidence that we identified at the time of finalizing each (December 2009 for the evidence brief and April 2011 for the issue brief). We determined that presenting the evidence from the original documents was the optimal approach as it provides a picture of what dialogue participants had reviewed before each of the stakeholder dialogues. However, we provided a monthly evidence service to stakeholders for one year following each dialogue, which kept them updated about new systematic reviews that had been published about each of the options in the briefs. The second limitation is that we were unable to engage our target size of 18 to 22 participants in each dialogue, with only 13 participants in the first dialogue and 16 in the second. In additon, we only engaged two policymakers in the first dialogue, which was the rationale to convene the second where we were able to engage six policymakers.

\section{Implications for policy}

The actionable messages coming out of these dialogues are clear: chronic pain management needs to be properly addressed in Canada and it is critical to engage leaders who can take action. Developing a national network and thereafter a national pain strategy are important initiatives that garnered broad-based support in the dialogues. Progress has been made towards these goals, although sustained efforts are required to build on this progress. In both dialogues, the idea of success stories or quick wins, which highlight the advantage of interventions, were identified as important next steps toward developing such a strategy.

\section{Implications for research}

What was apparent from the evidence and issue brief is that numerous research gaps exist. Whether the focus was the incidence and distribution of chronic pain in Canada, possible options to address problems with its management or key implementation considerations, there were few systematic reviews, and many of those that did exist were dated and of mixed quality. These gaps likely explain the assertion by dialogue participants that there is a lack of well-documented cases for why chronic pain is an important issue that health system decision makers should focus on. While there have been some efforts to this end, such as a book that provides a health policy perspective about chronic pain (29), the dialogue participants were speaking directly to the lack of awareness of such efforts, the need to supplement them with stories about how chronic pain affects the lives of those living with it, and documentation of the broader economic impact of chronic pain. In addition to this, future research may also be focused at: the level of people living with chronic pain by examining the implications of classifying chronic pain as a disease in Canada; the provider level by analyzing their perceptions to different initiatives or treatment of chronic pain; the organizational level by evaluating the effectiveness of approaches to providing comprehensive chronic pain management; and at the health system level by examining the feasibility of creating a national network or studying the impact of chronic pain policy portfolios.

ACKNOWLEDGEMENTS: The authors thank those involved with preparing the briefs and organizing the dialogues, who they formally acknowledge in the two briefs that are available on the McMaster Health Forum website (www.mcmasterhealthforum.org).

DISCLOSURES/FUNDING: The authors have no conflict of interest to declare. The work presented in this article was funded by the Community Alliances for Health Research and Knowledge Translation on Pain (CAHR-Pain). 


\section{REFERENCES}

1. Choiniere M, Dion D, Peng P, et al. The Canadian STOP-PAIN project - Part 1: Who are the patients on the waitlists of multidisciplinary pain treatment facilities? Can J Anaesth 2010;57:539-48.

2. Guerriere DN, Choiniere M, Dion D, et al. The Canadian STOPPAIN project - Part 2: What is the cost of pain for patients on waitlists of multidisciplinary pain treatment facilities? Can J Anaesth 2010;57:549-58.

3. Lynch ME. The need for a Canadian Pain Strategy. Pain Res and Manag 2011;16:77-80.

4. Dobkin PL, Boothroyd, LJ. Management of Chronic (Non-Cancer) Pain Organization of Health Services. Montreal, QC: Agence d'Evaluation des Technologies et des Modes d'Intervention en Sante (AETMIS); 2006.

5. Moulin DE, Clark AJ, Speechley M, Morley-Forster PK. Chronic pain in Canada: Prevalence, treatment, impact and the role of opioid analgesia. Pain Res Manag 2002;7:179-84.

6. Schopflocher D, Taenzer P, Jovey R. The prevalence of chronic pain in Canada. Pain Res Manag 2011;16:445-50.

7. Hadjistavropoulos T, Gibson S, Fine PG. Pain in older persons: A brief clinical guide. In: Lynch ME, Craig KD, Peng PW, eds. Clinical Pain Management. Wiley-Blackwell, 2010;309-18.

8. Hadjistavropoulos T, Marchildon GP, Fine PG, et al. Transforming long-term care pain management in North America: The policyclinical interface. Pain Med 2009;10:506-20.

9. Institute of Medicine. Relieving pain in America: A blueprint for transforming prevention, care, education and research. Washington DC: Institute of Medicine, National Academies Press, 2011.

10. Moat KA, Lavis JN, Clancy SJ, El-Jardali F, Pantoja T. Evidence briefs and deliberative dialogues: Perceptions and intentions to act on what was learnt. Bull World Health Organ 2014;92:20-8.

11. Wilson MG, Lavis JN. Issue brief: Engaging health system decisionmakers in supporting comprehensive chronic pain management in provincial and territorial healthcare systems in Canada. Hamilton, Canada: McMaster Health Forum, 2011.

12. Lavis JN, Boyko J. Evidence brief: Supporting chronic pain management in provincial and territorial health systems in Canada. Hamilton, Canada: McMaster Health Forum, 2009.

13. ACTION Ontario. ACTION Ontario: For people with NeuroPathic Pain. ACTION Ontario. <www.actionontario.ca/en/ home.html> (Accessed January 14, 2014).

14. Canadian Institute for Health Information. Canadian Institute for Health Information. <www.cihi.ca/CIHI-ext-portal/internet/EN/ Home/home/cihi000001> (Accessed January 3, 2014).

15. Canadian Pain Society. Canadian Pain Society. <www. canadianpainsociety.ca> (Accessed January 3, 2014).

16. European Observatory on Health Systems and Policies. European Observatory on Health Systems and Policies. <www.euro.who.int/ en/about-us/partners/observatory> (Accessed January 3, 2014).

17. Health Council of Canada. Health Council of Canada. $<$ www.healthcouncilcanada.ca/> (Accessed January 3, 2014).

18. Health Policy Monitor. Health Policy Monitor. Bertelsmann Stiftung Foundation. <http://hpm.org/> (Accessed January 3, 2014).

19. Institute for Clinical Evaluative Sciences. ICES: Evidence Guiding Healthcare. Institute for Clinical Evaluative Sciences. <www.ices. on.ca/> (Accessed January 3, 2014).

20. Queen's Printer for Ontario. Health Quality Ontario. Health Quality Ontario. <www.hqontario.ca/> (Accessed January 3, 2014).

21. Organisation for Economic Cooperation and Development. OECD; Better Policies for Better Lives. Organisation for Economic Cooperation and Development. < www.oecd.org/canada/> (Accessed January 3, 2014).

22. McMaster Health Forum. Health Systems Evidence: Why use it and who's behind it? McMaster Health Forum.

$<$ www.healthsystemsevidence.org/why-use-it.aspx > (Accessed January 3, 2014).

23. Shea B, Grimshaw J, Wells G, et al. Development of AMSTAR: A measurement tool to assess the methodological quality of systematic reviews. BMC Med Res Methodol 2007;7:10-6.

24. Lavis JN. Dialogue summary: Supporting chronic pain management across provincial and territorial health systems in Canada. Hamilton, Canada: McMaster Health Forum, 2009.
25. Wilson MG, Lavis JN. Dialogue summary: Engaging health system decision-makers in supporting comprehensive chronic pain management in provincial and territorial healthcare systems in Canada. Hamilton, Canada: McMaster Health Forum, 2011.

26. Canadian Pain Society. Update on the National Pain Strategy January 2013. <www.canadianpaincoalition.ca/media/national_ pain_strategy.pdf> (Accessed August 10, 2015).

27. Pain Australia. Pain Australia: Working to prevent and manage pain. <www.painaustralia.org.au/the-national-pain-strategy/ national-pain-strategy.html> (Accessed January 3, 2014).

28. Eyles J, Stoddart GL, Lavis JN, Pranger T, Molyneaux-Smith L, McMullan C. Making resource shifts supportive of the broad determinants of health: The PEI Experience. Ottawa, Canada: Canadian Health Services Research Foundation, 2001.

29. Rashiq S, Schopflocher D, Taenzer P, Jonsson E. Chronic pain: A health policy perspective. Wiley Online Library, 2008.

30. Ramage-Morin PL. Chronic pain in Canadian seniors. Health Rep 2008;19:1-16.

31. Statistics Canada. CANSIM Table 105-0501: Health indicator profile, annual estimates, by age group and sex, Canada, provinces, territories, health regions (2007 boundaries) and peer groups, occasional. Canadian Community Health Survey 2009.

32. Peng P, Choiniere M, Dominique D, et al. Challenges in accessing multidisciplinary pain treatment facilities in Canada. Can J Anaesth 2007;54:977-84.

33. McGillion MH, leFort S, Stinson J. Chronic pain self-management. Chronic Pain. Wiley-VCH Verlag GmbH \& Co. KGaA, 2008;167-81.

34. McGillion MH, Watt-Watson J, Stevens B, Lefort SM, Coyte P, Graham A. Randomized controlled trial of a psychoeducation program for the self-management of chronic cardiac pain. J Pain Symptom Manage 2008;36:126-40.

35. Fung CH, Lim YW, Mattke S, Damberg C, Shekelle PG. Systematic review: The evidence that publishing patient care performance data improves quality of care. Ann Intern Med 2008;148:111-23.

36. O'Connor AM, Rostom A, Fiset V, et al. Decision aids for patients facing health treatment or screening decisions: Systematic review. BMJ 1999;319:731-4.

37. Gysels M, Richardson A, Higginson IJ. Does the patient-held record improve continuity and related outcomes in cancer care: A systematic review. Health Expect 2007;10:75-91.

38. Warsi A, LaValley MP, Wang PS, Avorn J, Solomon DH. Arthritis self-management education programs: A meta-analysis of the effect on pain and disability. Arthritis Rheum 2003;48:2207-13.

39. Balas EA, Krishna S, Kretschmer RA, Cheek TR, Lobach DF, Boren SA. Computerized knowledge management in diabetes care. Med Care 2004:42:610-21.

40. Tran K, Polisena J, Coyle D, et al. Home telehealth for chronic disease management. Ottawa, Canada: Canadian Agency for Drugs and Technologies in Health, 2008.

41. Dorr D, Bonner LM, Cohen AN, et al. Informatics systems to promote improved care for chronic illness: A literature review. J Am Med Inform Assoc 2007;14:156-63.

42. Henrotin YE, Cedraschi C, Duplan B, Bazin T, Duquesnoy B. Information and low back pain management: A systematic review. Spine 2006;31:326-34

43. Handoll HH, Cameron ID, Mak JC, Finnegan TP. Multidisciplinary rehabilitation for older people with hip fractures. Cochrane Database Syst Rev 2009;(4):CD007125.

44. Riemsma RP, Kirwan JR, Taal E, Rasker JJ. Patient education for adults with rheumatoid arthritis. Cochrane Database Syst Rev 2003;(2):1-113.

45. Foster G, Taylor SJ, Eldridge S, Ramsay J, Griffiths C. Selfmanagement education programmes by lay leaders for people with chronic conditions. Cochrane Database Syst Rev 2007;(4):1-80.

46. Verhoeven F, Gemert-Pijnen L, Dijkstra K, Nijland N, Seydel E, Steehouder M. The contribution of teleconsultation and videoconferencing to diabetes care: A systematic literature review. J Med Internet Res 2007;9:e37.

47. Ospina M, Harstall C. Multidisciplinary pain programs for chronic pain: Evidence from systematic reviews. Edmonton, Canada: Alberta Heritage Foundation for Medical Research (AHFMR), 2003. 
48. National Pain Summit Initiative (Australian and New Zealand College of Anaesthetists FoPMAPSaCPA. National Pain Strategy: Pain Management for All Australians. Waverly, NSW, Australia: Pain Australia, 2010

49. ACTION Ontario. Rallying together to ease the pain: ACTION Ontario brings together patients and experts to discuss the needs of Ontarians with chronic pain. CNW Group November 9, 2010; $<$ www.newswire.ca/en/releases/archive/November2010/09/c2419. html> (Accessed August 10, 2015).

50. Grilli R, Ramsay C, Minozzi S. Mass media interventions: Effects on health services utilisation. Cochrane Database Syst Rev 2002;(1):CD000389.

51. Vidanapathirana J, Abramson MJ, Forbes A, Fairley C. Mass media interventions for promoting HIV testing. Cochrane Database Syst Rev 2005;CD004775.

52. Smith KE, Bambra C, Joyce KE, Perkins N, Hunter DJ, Blenkinsopp EA. Partners in health? A systematic review of the impact of organizational partnerships on public health outcomes in England between 1997 and 2008. J Public Health 2009;31:210-21.

53. Doumit G, Gattelari M, Grimshaw J, O’Brien MA. Local opinion leaders: Effects on professional practice and health care outcomes. Cochrane Database Syst Rev 2007;(1): CD000125.

54. van der Wees PJ, Jamtvedt G, Rebbeck T, de Bie RA, Dekker J, Hendriks EJ. Multifaceted strategies may increase implementation of physiotherapy clinical guidelines: A systematic review. Aust J Physiother 2008;54:233-41.
55. Thomas LH, Cullum N, McColl E, Rousseau N, Soutter J, Steen N. Guidelines in professions allied to medicine. Cochrane Database Syst Rev 2000;(2):CD000349.

56. Chaillet N, Dubé E, Dugas M, et al. Evidence-based strategies for implementing guidelines in obstetrics: A systematic review. Obstetr Gynecol 2006;108:1234-45.

57. Stoddart GL, Chaulk P, Eyles J, et al. PEI System Evaluation Project: Decision Support Tool 1. A Conceptual Framework for Cross-sectoral Reallocation of Resources for Health. Charlottetown (PEI): PEI Department of Health and Social Services, 1998.

58. Eyles J, Chaulk P, Gallant D, et al. PEI System Evaluation Project: Decision Support Tool 2. Scan and Plan: Meeting and Managing Potential Challenges to Cross-sectoral Reallocation. Charlottetown (PEI): PEI Department of Health and Social Services, 1998.

59. Pranger T, MacDonald J, Chaulk P, et al. PEI System Evaluation Project: Decision Support Tool 3. Facilitating Staff Involvement in the Shift to Cross-sectoral Reallocation. Charlottetown: PEI Department of Health and Social Services, 1998.

60. Rachlis MM, Chaulk P, Eyles J, et al. PEI System Evaluation Project: Decision Support Tool 4. Preparing for Media Communications about Cross-sectoral Reallocation.

Charlottetown: PEI Department of Health and Social Services; 1998.

61. Stoddart GL, Chaulk P, Eyles J, et al. PEI System Evaluation Project: Decision Support Tools for Cross-sectoral Investments in Population Health in the Context of Health System Change. Charlottetown: PEI Department of Health and Social Services, 1998. 


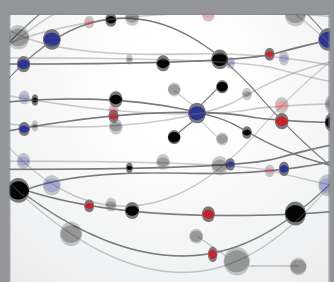

The Scientific World Journal
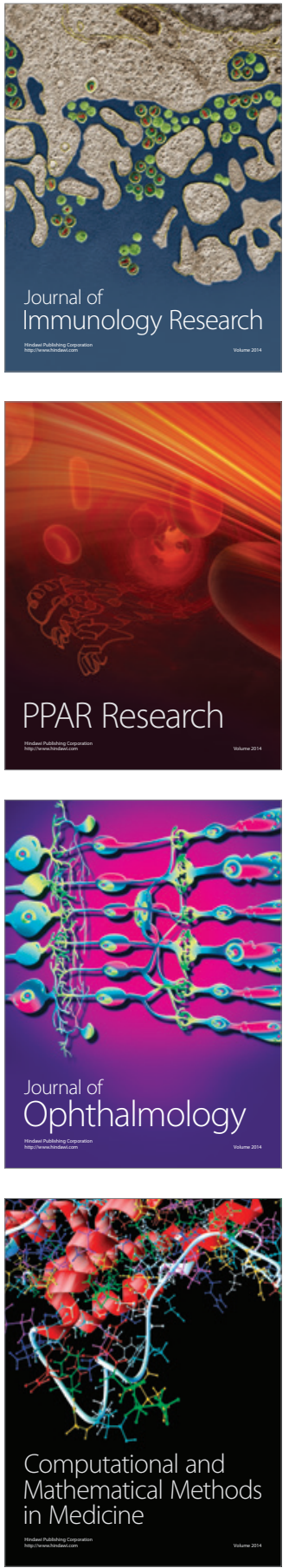

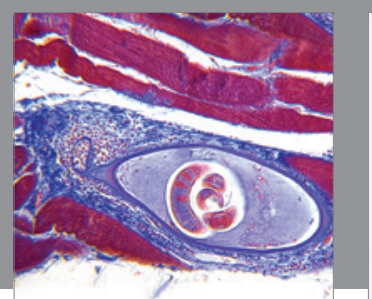

Gastroenterology Research and Practice

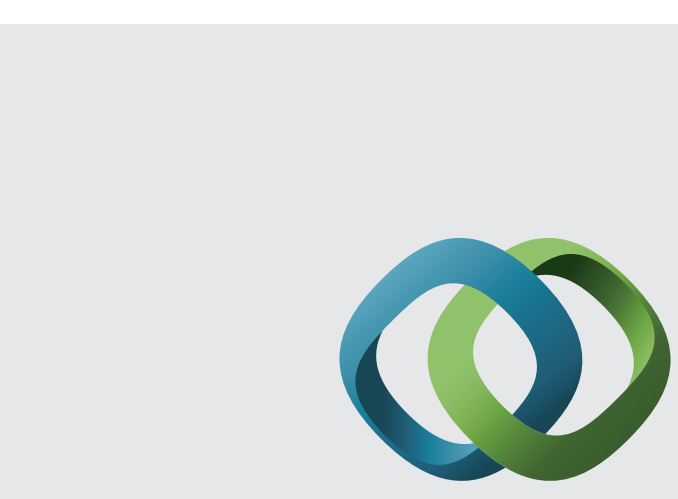

\section{Hindawi}

Submit your manuscripts at

http://www.hindawi.com
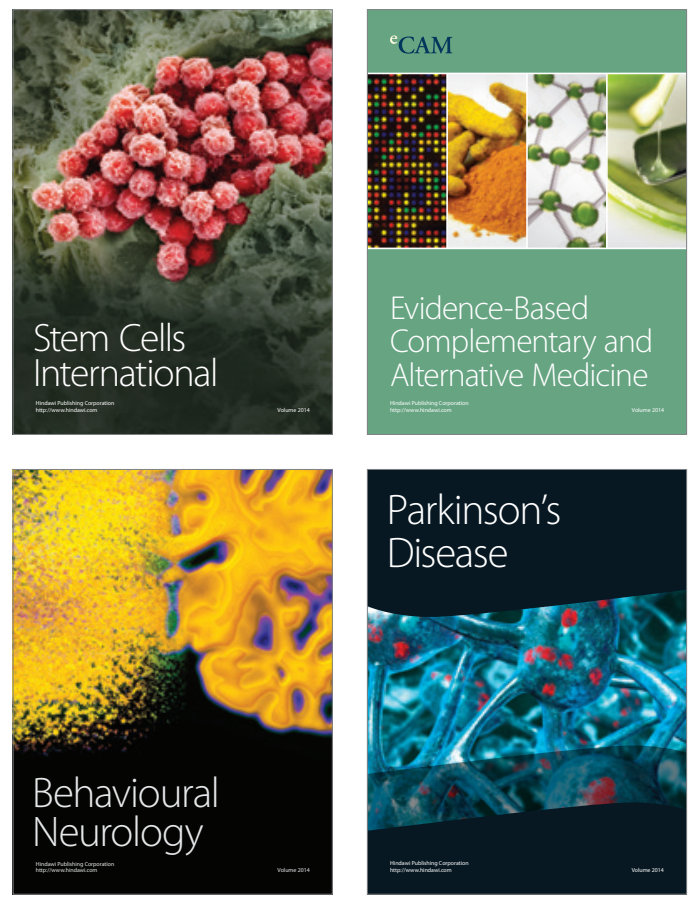
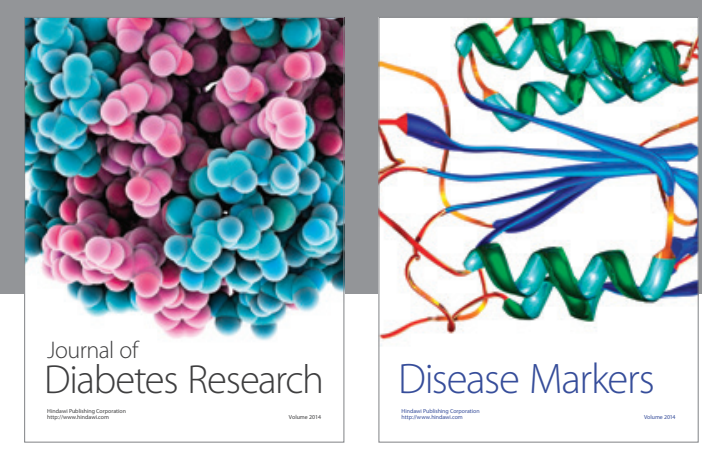

Disease Markers
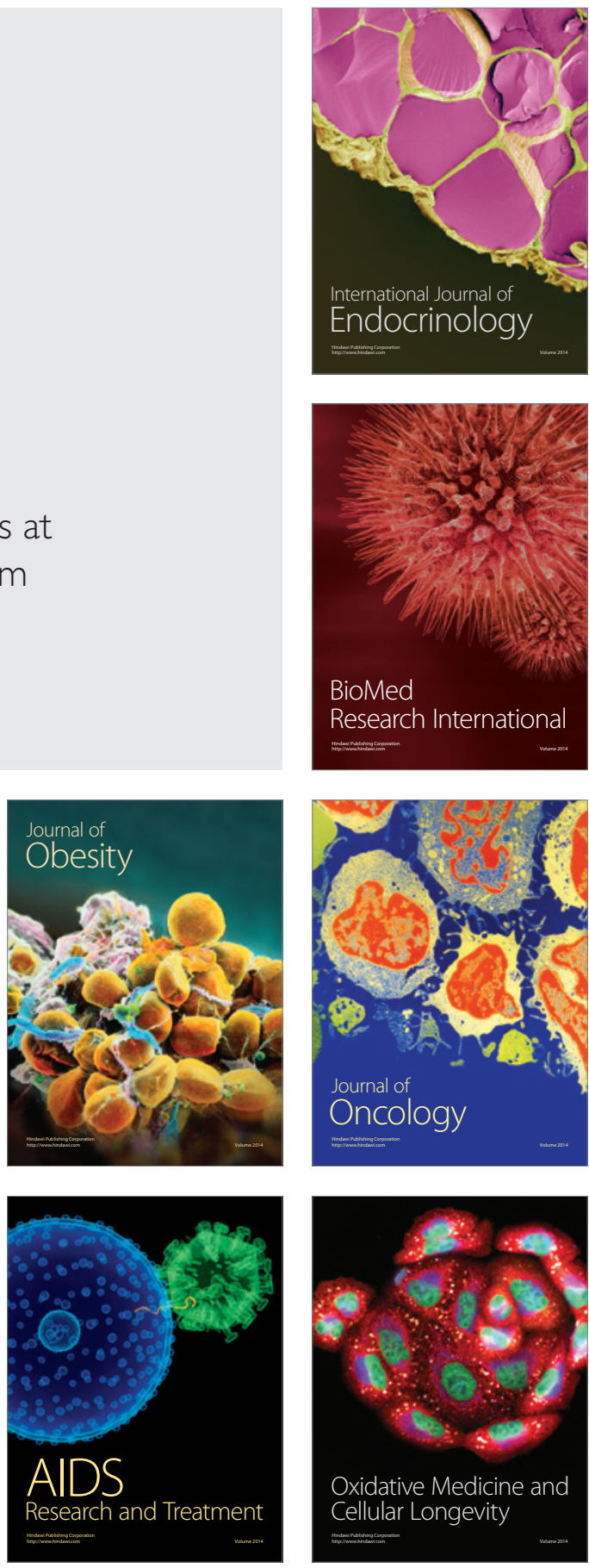